\title{
COMPARING THE CULTURAL DIMENSIONS AND LEARNERS' PERCEIVED EFFECTIVENESS OF ONLINE LEARNING SYSTEMS (OLS) AMONG AMERICAN AND MALAYSIAN LEARNERS
}

\author{
Seng C. Keng
}

\begin{abstract}
With the rapid and exponential growth of Internet use worldwide, online learning has become one of the most widely used learning paradigms in the education environment. Yet despite the rapidly increasing cultural diversity of online learners, few studies have investigated the effectiveness of cross-cultural Online Learning Systems (OLS) using a suitable measurement to answer the question, "Do culturally different learners perceive OLS effectiveness differently?" The aim of this comparative study was to gain a better understanding of OLS effectiveness in a non-western culture by comparing cultural dimensions and learners' perceived effectiveness of OLS (across the four pillars: technology/support, course, professor, \& learner) among American and Malaysian learners. Results show that American learners perceived a slightly higher OLS effectiveness in terms of the course and professor pillars than Malaysian learners. In other words, the findings indicated that the cultural dimensions distinguishing American and Malaysian learners influenced those two groups' perceived effectiveness of the course and professor pillars of the OLS.
\end{abstract}

\section{KEYWORDS}

Online learning systems (OLS); Cultural dimensions; Perceived effectiveness of OLS

\section{INTRODUCTION}

The rapid growth of Internet use, combined with advancements in information technology, have changed all aspects of our daily lives. One area of notable change has been the education environment, where Internet technology has caused a shift in learning paradigms [59]. Today, online learning has become one of the most widely used learning paradigms in the education environment [10]. However, online learning also faces great challenges due the increasingly diverse and cross-cultural nature of the learning environment [17]. These challenges have raised awareness of the complexities associated not only with cross-cultural learning but also with the use of an Online Learning Systems (OLS) model developed in a western culture [7].

The growing interest in OLS in non-western countries, in western countries among higher academic institutions with multi-cultural learner bases, as well as in international organizations has created a critical and central need for studies of OLS effectiveness that take a cross-cultural approach [7]. Sánchez-Franco, Martínez-López, and Martín-Vekicia [52] have suggested that learners' cultural backgrounds can potentially influence their perceptions of OLS effectiveness, or as Bowers [8] noted over a decade ago, technology is not "culturally neutral." Reinforcing this idea, studies in cross-cultural psychology have found that many ideas concerning learners' beliefs and behavior formulated based upon studies in western countries cannot be generalized to nonwestern societies [12]. Since the general cultural norms of one country may differ in various 
International Journal of Computer Science \& Information Technology (IJCSIT) Vol 10, No 1, February 2018

degrees from those of other countries, it appears that the findings of past OLS studies may not necessarily apply to non-western countries [65]. Yet, it has long been clear that valid crosscultural comparisons of OLS effectiveness are lacking [2]. The results of such a lack may be misguided decision-making regarding the development, acquisition, delivery, and implementation of OLS [10]. The fact is that most current commercial OLS developed in western cultures may not be considered equally effective when adopted by a non-western culture. Thus, the problem is the limited evidence that western-based OLS models are effective in non-western countries

According to Bray et al. [7] and Levy [44], interest in OLS is increasing, with many higher academic institutions and private organizations now investing significant capital in OLS. OLS has become an increasingly important aspect of higher academic institutions, governments, and international organizations as they attempt to meet the needs of an expanding pool of traditional and nontraditional learners [40] The most common types of OLS are asynchronous, synchronous, and mixed learning systems [42]. In IS literature, the term OLS often refers to all such asynchronous, synchronous, or mixed learning systems. In instructional technology literature, an OLS is also referred to as a Learning Management System (LMS) or Course Management System (CMS).

\section{THEORETICAL BACKGROUND}

IS literature contains two established user satisfaction models: Bailey and Pearson's [4] user information satisfaction (UIS) and Doll and Torkzadeh's [14] end-user computing satisfaction (EUCS). According to Wang [58], most OLS effectiveness studies have utilized UIS and EUCS as surrogate measures of OLS effectiveness. However, these models were developed in western countries and have largely received their validation through application in western countries. According to Zhang et al. [65], attempting to apply western models to non-western countries may not be valid. Theories and models that were developed in western countries might potentially have different or contradicting results when applied to another culture [41],[64]. Further, measures and models developed in prior research using learners from western cultures may not be directly applicable to, or may require adjustment, in other cultures. In order to make valid comparisons, Lee and Lee [41] have suggested that models developed in western countries be tested for robustness across cultures. Levy's [44] study pointed out that many scholars have criticized these models as being either inapplicable or unsuitable for OLS, or for omitting items of the degree of importance of the measured OLS characteristics. OLS characteristics are defined in this study as the attributes or features associated with OLS [44]. For instance, Etezadi-Amoli and Farhoomand [20] have criticized EUCS and UIS for not including user beliefs in the measurement of user satisfaction. They further argued that including such measurements on user beliefs will provide a better understanding of IS effectiveness.

Doll and Torkzadeh [15] conceptualized general IS user satisfaction as "the affective attitude towards a specific computer application by someone who interacts with the application directly" (p. 261). In turn, Bailey and Pearson [4] defined satisfaction as "the sum of the user's weighted reactions to a set of characteristics" (p. 531). Another definition of satisfaction in the context of OLS comes from research by Levy [44], wherein satisfaction is defined as "the perceived performance level users find at a post-experience point of time with e-learning systems" (p. 88). This study followed Levy's [44] definition of IS satisfaction in the context of OLS.

According to research conducted by Chen et al. [10] and Lee \& Lee [41], different cultural dimensions might have a direct or indirect influence on a learner's perceived OLS effectiveness. According to the classical work by Hofstede [29], cultural dimensions permeate every aspect of individual daily life and can have a significant influence on many situations, such as learner perceptions. Due to the potentially different exigencies different cultural dimensions may exert, 
International Journal of Computer Science \& Information Technology (IJCSIT) Vol 10, No 1, February 2018

these dimensions need to be considered in any form of cross-cultural communication [65]. The consideration of cultural dimensions is important with OLS because OLS is popular in universities across many cultures, yet most OLSs used in non-western cultures were developed in western ones.

There are deep-rooted differences in how cultural dimensions might affect a learner's perceived OLS effectiveness [1],[48],[57]. A number of studies have suggested that cultural dimensions may influence learners' perceived OLS effectiveness [1],[11],[57]. Yet, very little attention has been given to comparing these cultural dimensions with learners' perceived OLS effectiveness [10]. According to Gallivan and Srite [23], most research in IS has examined the implications of different cultural dimensions on various systems, such as group support systems (GSS), knowledge management systems (KMS), and videoconferencing. However, little attention has been given to OLS in terms of perceived effectiveness across different cultural dimensions.

\subsection{Culture and Cultural Dimensions}

Culture is a complex construct that can be studied on many levels, such as the organizational, regional, and national [55]. In past literature, researchers have defined culture in various ways. However, this study followed the seminal work by Hofstede [29],[30],[31],[32],[33] and defined culture as "the collective programming of the mind which distinguishes the members of one group or category of people from another" (p. 260). Hofstede conceptualized culture through five cultural dimensions: (a) Power Distance dimension (PDD); (b) Individualism/Collectivism dimension (ICD); (c) Masculinity/Femininity dimension (MFD); (d) Uncertainty Avoidance dimension (UAD); and (e) Long/Short Term Orientation dimension (LSOD). Although many frameworks for measuring culture have been developed, Hofstede's cultural dimensions taxonomy was derived from research exploring 88,000 respondents from over 60 countries. Hofstede's [29],[30],[31],[32],[33] cultural dimensions have been widely validated and extensively employed in IS research [11],[60]. Based on Hofstede's [29],[30],[31] cultural dimensions, American and Malaysian cultures are differentiated as indicated in Table 1.

Table 1. Hofstede's Cultural Dimensions

\begin{tabular}{lcc}
\hline Cultural Dimensions & American & Malaysian \\
\hline PDD & 40 & 104 \\
ICD & 91 & 26 \\
MFD & 62 & 50 \\
UAD & 46 & 36 \\
LSOD & 29 & $\mathrm{n} / \mathrm{a}$ \\
\hline
\end{tabular}

\subsubsection{The Power Distance Dimension}

Hofstede suggested that the PDD has tremendous ramifications in education. The PDD score for Americans is noted as 40, compared to 104 for Malaysians (in this category, 104 being the highest and 11 being the lowest). In a high PDD society, such as that of Malaysia, instructors and learners tend not to be perceived as equal [6]. Further, in a high PDD society as in Malaysia learning is perceived as largely a one-way process wherein instructors are authorities who pass along knowledge to learners, while learners do not question that authority [6]. Therefore, in Malaysian culture learners rely on their instructor for their education. In a low PDD society, such as in the United States, instructors and learners are perceived more equally. Further, in a low PDD society, learners perceive their instructors more as facilitators, while learners are still expected to demonstrate initiative, originality, and to develop their own knowledge [6]. 
International Journal of Computer Science \& Information Technology (IJCSIT) Vol 10, No 1, February 2018

\subsubsection{The Individualism/Collectivism Dimension}

The ICD score for Americans is noted as 91, compared to 26 for Malaysians (91 being the highest and six the lowest for this category). In the ICD dimension, a high score represents individualism while a lower score represents collectivism. In an individualist society, most learners prefer to work individually and they are treated more or less equally. In addition, learners in an individualist society view education as a way to becoming more independent and increasing their economic worth [6]. On the other hand, in a collectivist society, learners prefer to take responsibility as a group rather than as individuals. Further, in a collectivist society, learners' primary purpose or aim in learning is to secure a place in society and generate social status [6].

\subsubsection{The Masculinity/Femininity Dimension}

The MFD score for Americans is noted as 62, compared to 50 for Malaysians (110 being the highest and five being the lowest in this category). In the MFD dimension, a high score represents masculinity while a lower score represents femininity. In a masculine society, learners are achievement conscious, seek high grades, and hold reputation as very important [6]. On the other hand, in a feminine society, learners are less aggressive goal achievers and being average is perceived as acceptable [6].

\subsubsection{The Uncertainty Avoidance Dimension}

The UAD score for Americans is noted as 46, compared to 36 for Malaysians (112 being the highest and eight being the lowest in this category). In a strong uncertainty avoidance society, the instructor is the expert and ultimate authority. The learner in a strong UAD society prefers a structured learning environment with precise objectives, detailed assignments, and precise answers [6]. On the other hand, in a weak uncertainty avoidance society, the instructor is sociable and amenable to openness with learners. The learner in a weak UAD culture is more comfortable with broad objectives and multiple solutions to a problem [6].

\subsubsection{The Long/Short Term Orientation Dimension}

The LSOD score for Americans is noted as 29, while there is as yet no score for Malaysians (118 being the highest and 16 being the lowest in this category). Therefore, this study will need to determine the LSOD score for Malaysian culture. LSOD is the fifth of Hofstede's five cultural dimensions. LSOD was added as a dimension after the original four failed to fully distinguish differences in thinking between eastern and western cultures [30].

\subsection{IS Effectiveness}

According to Au, Ngai, and Cheng [3], as well as [24], measuring IS effectiveness remains a critical concern for both academia and IS practitioners. To begin with, there is little agreement even on the definition of IS effectiveness. Further, measuring IS effectiveness is no easy task [15][24][36][53]. Therefore, many researchers have adopted an indirect approach, such as measuring UIS, quality of decision making, productivity from cost/benefit analysis, and system quality as a surrogate measure of IS effectiveness [24]. However, due to the difficulty in quantifying and linking costs and benefits to particular IS innovations, measures based on system usage and user perception have become prominent within IS literature [24]. According to [24], some researchers have suggested user satisfaction is more preferable than IS usage as a surrogate of IS effectiveness. They argue that the relationship between usage and the quality of decisionmaking tends to be weak. For these reasons, a significant amount of research has been devoted to developing and refining measures of user satisfaction [4],[5],[24],[36]. 
International Journal of Computer Science \& Information Technology (IJCSIT) Vol 10, No 1, February 2018

\subsection{OLS Effectiveness}

According to Levy [44] and Sun [57], many higher academic institutions and international organizations are now investing significant capital in OLS, and interest in OLS is rapidly expanding. Currently OLS is the most widely adopted format in developing countries due to its flexibility and the overall quality of online learning [45]. Even though OLS is one of the most significant developments in the IS industry, the methods of measuring OLS effectiveness continue to be a critical issue on an international and multi-cultural level such effectiveness cannot be evaluated based on any single item scale, such as global satisfaction [58].

Since the 1980s, user satisfaction has received considerable attention as an important surrogate measure of overall IS effectiveness [4],[35],[36],[44],[63]. The UIS and EUCS have been the most popular measurement instruments for measuring user satisfaction [13]. However, both UIS and EUCS are relatively dated and end-user computing has dramatically changed over the decades since their inception [13][63]. According to Xiao and Dasgupta [63] as well as Wang [58], both UIS and EUCS might be unsuitable for Web-based information systems because UIS and EUCS were not developed for the OLS context. Further, UIS and EUCS have been criticized for omitting items of the degree of importance of measured OLS characteristics [44].

According to Wang [58], valid cross-cultural comparisons of OLS effectiveness are still lacking because most studies have been narrowly focused on samples from western cultures. As a result, their findings cannot be generalized globally due to potential differences when applied to another culture [11],[26],[41],[65]. According to Hofstede and Bond [34], the general cultural values of one country may differ from those of another. Rokeach [49] has defined value as a type of belief that is "centrally located within one's total belief system, about how one ought or ought not to behave" (p. 124). Consistent with existing OLS literature, this study will define value as the "enduring core belief about the level of importance learners attribute to OLS as a whole" [43](p. 295). According to Kahle and Kennedy [38], values cause attitudes, which in turn cause behavior. Many behavioral scientists have applied value concepts as predictors of consumer behavior [28], organizational behavior [46], job-seeking behavior [22], etc. According to Levy [44], the significance of value research is clearly demonstrated; however, value as a construct in current IS literature is still lacking. In response to this need for a value construct, Levy [44] has developed a framework that includes value construct to measure IS effectiveness, specifically for OLS. However, additional research is needed to investigate OLS effectiveness in a cross-cultural context.

\subsection{Perceived Satisfaction}

Measuring IS effectiveness is extremely difficult [4],[5],[9],[36],[54]. Consequently, researchers have turned to measuring user satisfaction as a surrogate measure of IS effectiveness. According to Ives et al. [36], user satisfaction is a more feasible surrogate of IS effectiveness. Therefore, during the 1980s user satisfaction became a pervasive measure of IS effectiveness [13]. In 1983, Ives et al. [36] developed UIS based on research conducted by Bailey and Pearson [4]. However, Doll and Torkzadeh [14] claimed that the UIS instrument focused solely on specific applications rather than the end-user in general. In response to this, they developed EUCS. The next section will provide an overview of the UIS and EUCS instruments along with a discussion of their limitations.

\subsection{UIS and EUCS Instruments}

Bailey and Pearson [4] developed UIS to measure and analyze computer user information satisfaction. Initially, Bailey and Pearson compiled a list of 36 distinct survey items from past 
International Journal of Computer Science \& Information Technology (IJCSIT) Vol 10, No 1, February 2018

computer and user satisfaction studies [44][61]. After the compilation of these 36 survey items, professionals were then asked to review and rank the importance of each survey item. Based on the results, Bailey and Pearson concluded that UIS needed to be supplemented by three additional characteristics. Therefore, their final list contained 39 survey items affecting and reflecting user information satisfaction [9],[44],[61].

Later, Ives et al. [36] conducted a follow-up study on Bailey and Pearson's UIS in an effort to improve its consistency and reliability. Ives et al. [36] eliminated those survey items with lower correlations to the overall measure, including the measurement of the importance level of the characteristics to the user. Ives et al. [36] claimed that the level of importance measurement was redundant and provided little information on user satisfaction. However, Etezadi-Amoli and Farhoomand [20] disagreed with Ives et al., claiming that measurement of the importance level can actually provide a better understanding of user satisfaction. Kettinger and Lee [39] also criticized Ives et al.'s UIS for omitting the service quality. In addition, they also claimed that Ives et al.'s UIS had validity and reliability because it focused specifically on data processing systems rather than the general personal computing environment [39]. Another limitation of UIS is that its measuring scale is semantic differential rather than the Likert scale type. Due to these limitations, UIS does not enjoy the popularity of Doll and Torkzadeh's [14],[15] EUCS among researchers [63].

According to Doll and Torkzadeh [14], the UIS focuses mainly on evaluating specific rather than general applications. In response to this, Doll and Torkzadeh [14],[15] developed the EUCS to measure general satisfaction. EUCS contains 12 items and is comprised of five components: (a) content; (b) accuracy; (c) format; (d) ease of use; and (e) timeliness. Many subsequent studies have confirmed the reliability and validity of the EUCS measurement. Despite EUCS's popularity and the confirmation of its reliability and validity by subsequent studies, EUCS has also been criticized for its lack of measurements of service quality and technical support [53]. Another criticism is that the EUCS measures the frequency of satisfaction rather than the extent of satisfaction with the characteristics of a given application [20]. Therefore, additional research is needed to investigate the measurement of OLS effectiveness using an instrument that overcomes the limitations of UIS and EUCS.

\subsection{Perceived Value}

Value has been defined in variant ways in past literature. Rokeach [49] claimed value as the core conception of the desirable within the individual and every society, further stating that value is the main dependent variable in the study of personality, society, and culture. Further, Rokeach [49] also argued that value served as a standard for guiding an individual's actions, judgments, choices, attitudes, evaluations, arguments, exhortations, rationalizations, and attributions of causality. In 1973, Rokeach defined value as "an enduring belief that a specific mode of conduct or end-state of existence is personally or socially preferable to an opposite or converse mode of conduct or end-sate of existence" (p. 5). However, Feather [21] criticized Rokeach's [53] use of the term belief in his definition because he considered belief to be a neutral concept. Accordingly, Feather [21] redefined Rokeach's [53] definition of value as, "beliefs about the desirables and therefore, involve some knowledge about the means or ends considered to be desirable" (p. 5). Another definition of value comes from Munson and Posner [46], who noted that what individuals consider to be important to them is called value. Consistent with past literature, and in the context of OLS, this study will define value as "the enduring principals learners use to evaluate the importance of OLS characteristics" [44] (p. 22).

According to Rokeach [53], scholars had largely neglected the concept of value and placed too much attention on the concept of attitude. He argued that value served as an important criteria by which a person evaluated ideas, objects, and actions; while attitude did not. Rokeach further 
International Journal of Computer Science \& Information Technology (IJCSIT) Vol 10, No 1, February 2018

claimed that value was centrally located in an individual's cognitive system, impacting attitude and satisfaction. He suggested value to be the determinant of attitude and behavior. The two satisfaction models UIS and EUCS do not include a value construct, a focus of criticism of some scholars. These critics argue that including a value construct will provide a better understanding of IS effectiveness.

\subsection{Learners' Value Index of Satisfaction (LeVIS)}

LeVIS was developed specifically for OLS [44]. LeVIS has four pillars with a 48 survey-item self-report survey instrument to measure both learners' perceived value and satisfaction for each OLS characteristic. These four pillars are: (a) technology/support; (b) course; (c) professor; and (d) learner. Consistent with the literature, this study will follow Levy's [44] definition of learner value as, "the importance of enduring core beliefs concerning each characteristic of OLS when learning online" (p. 295). LeVIS is more appropriate for this study compared to UIS and EUCS, as it includes the constructs of value and satisfaction in the context of OLS. According to Levy [44], most research from the psychology and marketing fields suggests that the value, attitude, behavior, and satisfaction constructs are closely related. According to Durgee, O'Conor, and Veryzer [16], value is an important concept as it impacts attitude which has an impact on behavior, which in turn impacts satisfaction. Similarly, Rokeach [50] has claimed that value is a determinant of attitudes and behavior. Rokeach further claimed that, "individuals derive satisfaction from expressing attitude appropriate to their personal values" [49](p. 130). Therefore, it is important to have a value construct in the context of OLS since value impacts attitude and satisfaction.

LeVIS is a tool for determining the effectiveness of an OLS. LeVIS includes questions measuring the perceived value and satisfaction of OLS characteristics as well as their respective four pillars. In this study, the results of measuring OLS characteristics and their four pillars will be aggregated across all learners. These aggregated measures will result in eight scores: two scores for each OLS pillar ( $\mathrm{Sa}, \mathrm{Sb}, \mathrm{Sc}, \mathrm{Sd}$ and $\mathrm{Va}, \mathrm{Vb}, \mathrm{Vc}, \mathrm{Vd}$ ). These scores will then be used to calculate the effectiveness of the technology/support pillar (Ea), course pillar (Eb), professor pillar (Ec), and learner pillar $(\mathrm{Ed})$.

\section{RESEARCH QUESTIONS}

The main research question this study addressed was: What are the differences in perceived OLS effectiveness (across the four pillars: technology/support, course, professor, and learner) between American and Malaysian learners based on Hofstede's five cultural dimensions? This study proposed five specific research questions:

RQ1: Are there significant differences in a learner's perceived OLS effectiveness (across the four pillars: technology/ support, course, professor, and learner) based on Hofstede's cultural Power Distance dimension (PDD)?

RQ2: Are there significant differences in a learner's perceived OLS effectiveness (across the four pillars: technology/ support, course, professor, and learner) based on Hofstede's cultural Individualism/ Collectivism dimension (ICD)?

RQ3: Are there significant differences in a learner's perceived OLS effectiveness (across the four pillars: technology / support, course, professor, and learner) based on Hofstede's cultural Masculinity/Femininity dimension (MFD)? 
International Journal of Computer Science \& Information Technology (IJCSIT) Vol 10, No 1, February 2018

RQ4: Are there significant differences in a learner's perceived OLS effectiveness (across the four pillars: technology/ support, course, professor, and learner) based on Hofstede's cultural Uncertainty Avoidance dimension (UAD)?

RQ5: Are there significant differences in a learner's perceived OLS effectiveness (across the four pillars: technology/ support, course, professor, and learner) based on Hofstede's cultural Long/Short Term Orientation dimension (LSOD)?

\subsection{Research Method and Sample}

This study utilized a comparative research design. It aimed to compare learners" cultural dimensions and their perceived effectiveness of OLS (across the four pillars: technology/support, course, professor, and learner) among American and Malaysian university learners. This study used a survey methodology to collect data from learners enrolled in American and Malaysian universities. More specifically, this study administered surveys to American and Malaysian university learners enrolled in courses utilizing OLS as their online learning environment.

The Web-based survey was created and then the uniform resource locator (URL), or hyperlink, to the survey was distributed to study participants. Validated survey items were adopted from Hofstede's cultural dimensions in order to measure cultural differences, while Levy's [44] LeVIS was used to measure learners' perceived OLS effectiveness. Hofstede's cultural dimension measurement was used for collecting data, which were then applied to a cultural dimension index to identify cultural differences between American and Malaysian learners. LeVIS was used for measuring learners' perceived OLS effectiveness.

The sample for this study consisted of two different cultural groups, namely American (United States) and Malaysian. More specifically, this study randomly chose learners from American and Malaysian universities that were taking courses using OLS. The target sample of this study was students of public and private universities from the University of Hawaii, Hawaii Pacific University, and the Universiti Tun Abdul Razak (UNITAR), Malaysia.

\subsection{Instrumentation and Data Collection}

There were three sections to this survey: (1) LeVIS; (2) Hofstede's cultural dimension measure; and (3) demographic information. The first part of the survey instrument consisted of 48 survey items to measure learners' perceived OLS effectiveness. In this LeVIS section, the survey items were divided into the four pillars of OLS: (a) technology/support; (b) course; (c) professor; and (d) learner. The five-point Likert scale (1-2-3-4-5) was used to indicate learners' level of satisfaction and levels of importance. The second part of the survey instrument consisted of 20 survey items designed to measure cultural dimensions and address the five different dimensions of culture. This study adapted the original five-point Likert scale from Hofstede [29][30][31]. The last part of the survey instrument collected the following demographic information from learners: current nationality, nationality at birth, gender, age, years of computer use, and number of online courses taken.

\subsection{Reliability}

To determine internal consistency across items for each construct, Cronbach's Alpha reliability tests were conducted for $\mathrm{Va}, \mathrm{Vb}, \mathrm{Vc}, \mathrm{Vd}, \mathrm{Sa}, \mathrm{Sb}, \mathrm{Sc}, \mathrm{Sd}, \mathrm{PDD}, \mathrm{ICD}, \mathrm{MFD}, \mathrm{UAD}$, and LSOD to determine consistency across items for each scale. The results demon-strated high Cronbach's $\alpha$ score for items, Except the PDD, UAD, and LSOD constructs demonstrated a Cronbach's $\alpha$ score slightly below .70 (see Table 2 ). 
Table 2. Reliability Test

\begin{tabular}{cclc}
\hline & LeVIS & \multicolumn{1}{c}{ Cultural Dimensions } \\
\hline Items & $\begin{array}{c}\text { Cronbach's } \\
\text { Alpha }\end{array}$ & \multicolumn{1}{c}{ Items } & Cronbach's Alpha \\
\hline $\mathrm{S}_{\mathrm{a}}$ & .859 & PDD & .671 \\
$\mathrm{~S}_{\mathrm{b}}$ & .882 & ICD & .748 \\
$\mathrm{~S}_{\mathrm{c}}$ & .878 & MFD & .740 \\
$\mathrm{~S}_{\mathrm{d}}$ & .852 & UAD & .689 \\
$\mathrm{~V}_{\mathrm{a}}$ & .836 & LSOD & .665 \\
$\mathrm{~V}_{\mathrm{b}}$ & .870 & & \\
$\mathrm{~V}_{\mathrm{c}}$ & .888 & & \\
$\mathrm{~V}_{\mathrm{d}}$ & .922 & & \\
\hline
\end{tabular}

\subsection{Results}

This study had approximately 500 survey participants from both American and Malaysian Universities. A total of 157 learners completed the survey, yielding a response rate of approximately $32 \%$. The gender rates of the final data set were approximately $49 \%$ male and $51 \%$ female. The participants in the final data set were approximately 57\% American and $43 \%$ Malaysian. The respondents represented all age ranges over 18, with the majority of respondents indicating the 20-29 year-old category. About 55\% of the respondents in the final data set were between the ages of $20-29$. About $27 \%$ of the respondents in the final data set were between the ages of 30-39. About $15 \%$ of the respondents in the final data set were between the ages 40-49. And about $3 \%$ of the respondents in the final data set were between the ages 50-59.

The ANOVA results for PDD, ICD, UAD, and LSOD cultural dimensions revealed a significant difference between American and Malaysian learners. The PDD found significant: $F(1,151)=$ 19.2, $\mathrm{p}<.001$; the ICD found significant: $\mathrm{F}(1,151)=5.3, \mathrm{p}=.023$; the UAD found significant: $\mathrm{F}(1,151)=8.4, \mathrm{p}=.004$; and the LSOD found significant: $\mathrm{F}(1,151)=14.9, \mathrm{p}<.001$. However, only one MFD result revealed no signification: $\mathrm{F}(1,151)=3.1, \mathrm{p}=.08$. Further, this study also established a LSOD score for Malaysia (39), a score not previously determined by Hofstede in 1980. The results of current cultural dimensions indexes are consistent with those from the study of Oshlyansky et al. in 2006.

Factorial ANOVA was used to determine any significant differences between the cultural dimensions' mean scores and each of the OLS pillars. The $\mathrm{Eb}(\mathrm{F}=4.9, \mathrm{p}=.029)$ and $\mathrm{Ec}(\mathrm{F}=5.2$, $\mathrm{p}=.025)$ both showed significant difference between American and Malaysian learners' perceived OLS effectiveness in the course and professor pillars. The results indicate that American learners have a slightly higher perceived OLS effectiveness in the course and professor pillars than do Malaysian learners. The $\mathrm{Ea}(\mathrm{F}=1.6, \mathrm{p}=.21)$ and $\mathrm{Ed}(\mathrm{F}=.1, \mathrm{p}=.82)$ both revealed no significant difference between American and Malaysian learners' perceived OLS effectiveness in the technology/support and learner pillars.

Table 3. Factorial ANOVA: Test of Between-Subject Effects

\begin{tabular}{|c|c|c|c|c|c|}
\hline \multicolumn{6}{|c|}{ Dependent Variable: $\mathrm{E}_{\mathrm{a}}$} \\
\hline Source & Type III Sum of Squares & Df & Mean Square & $\mathbf{F}$ & Sig. \\
\hline Corrected Model & $.01^{\mathrm{a}}$ & 1 & .01 & 1.6 & .206 \\
\hline Intercept & 33.63 & 1 & 33.63 & 6874.8 & $.000^{*}$ \\
\hline Nationality & .01 & 1 & .01 & 1.6 & .206 \\
\hline
\end{tabular}


International Journal of Computer Science \& Information Technology (IJCSIT) Vol 10, No 1, February 2018

\begin{tabular}{lrrr}
\hline Error & .73 & 150 & .01 \\
Total & 35.24 & 152 & \\
Corrected Total & .74 & 151 \\
R Squared =.011 (Adjusted R Squared $=.004)$ & & \\
\hline
\end{tabular}

\begin{tabular}{|c|c|c|c|c|c|}
\hline Source & Type III Sum of Squares & Df & Mean Square & $\mathbf{F}$ & Sig. \\
\hline Corrected Model & $.02^{\mathrm{a}}$ & 1 & .02 & 4.9 & $.029 * *$ \\
\hline Intercept & 28.58 & 1 & 28.58 & 6581.0 & $.000 *$ \\
\hline Nationality & .02 & 1 & .02 & 4.9 & $.029 * *$ \\
\hline Error & .65 & 150 & .00 & & \\
\hline Total & 30.10 & 152 & & & \\
\hline Corrected Total & .67 & 151 & & & \\
\hline \multicolumn{6}{|c|}{ R Squared $=.032($ Adjusted R Squared $=.025)$} \\
\hline \multicolumn{6}{|c|}{ Dependent Variable: $\mathbf{E}_{\mathbf{c}}$} \\
\hline Source & Type III Sum of Squares & Df & Mean Square & $\mathbf{F}$ & Sig. \\
\hline Corrected Model & $.03^{\mathrm{a}}$ & 1 & .03 & 5.2 & $.025 * *$ \\
\hline Intercept & 29.71 & 1 & 29.70 & 4460.3 & $.000 *$ \\
\hline Nationality & .03 & 1 & .03 & 5.2 & $.025 * *$ \\
\hline Error & .99 & 150 & .00 & & \\
\hline Total & 31.68 & 152 & & & \\
\hline Corrected Total & 1.03 & 151 & & & \\
\hline $\mathrm{R}$ Squared $=.033($ & sted R Squared $=.027$ ) & & & & \\
\hline
\end{tabular}

\begin{tabular}{|c|c|c|c|c|c|}
\hline \multicolumn{6}{|c|}{ Dependent Variable: $\mathbf{E}_{\mathbf{d}}$} \\
\hline Source & Type III Sum of Squares & Df & Mean Square & $\mathbf{F}$ & Sig. \\
\hline Corrected Model & $.00^{\mathrm{a}}$ & 1 & .00 & .1 & .820 \\
\hline Intercept & 28.99 & 1 & 28.98 & 3945.5 & $.000^{*}$ \\
\hline Nationality & .00 & 1 & .00 & .1 & .820 \\
\hline Error & 1.10 & 150 & .01 & & \\
\hline Total & 30.74 & 152 & & & \\
\hline Corrected Total & 1.10 & 151 & & & \\
\hline \multicolumn{6}{|c|}{ R Squared $=.000($ Adjusted R Squared $=-.006)$} \\
\hline
\end{tabular}

\section{STUDY LIMITATIONS}

This study had three primary limitations. The first was that the sample used was only a small portion of the online learner population for the two countries. It will be necessary to sample a larger population from the two cultures to increase the generalizability of this study or to further or deepen our understanding of how culture affects the perceived effectiveness of OLS.

A second limitation of this study concerns its use of the term "culture." The term "culture" can be a very problematic. A so-called national culture can in fact be composed of people of various 
International Journal of Computer Science \& Information Technology (IJCSIT) Vol 10, No 1, February 2018

cultures [56]. In response to this very criticism, Hofstede [32] defended the use of national culture (people living in the same country), which he maintained to still be a reasonably distinct cultural entity for the purpose of research.

A final limitation of this study is that its results may have been affected by learners' preferences concerning the survey format. Though all participants in this study were active in online learning, it is possible those who completed this study's survey were more comfortable using a computer than those who chose not to participate. Therefore, the results may have been affected by learner preferences.

\section{FUTURE RESEARCH}

The first potential area of research based on the results of this study would be an attempt to replicate this study in other settings, such as in the collaborative environment of international organizations. This would potentially serve to increase the generalizability of the results of this study. A second potential focus of research this study could engender would be an attempt to include additional independent variables, such as academic major, enrollment status (full or part time), first language, graduate students, grade point average, etc. The addition of these variables might provide additional insights to the factors affecting learners' perceived OLS effectiveness. A third research study that might result from this study would be an attempt to replicate the current study using a larger sample with multiple locations and cultures. This would diversify the numbers of institutions represented while making it potentially easier to solicit more participants. This should also be considered in order to increase the generalizations of the results. A final research study that might result from this current study would be an attempt to replicate the current study at a future date. This could be done after a passage of approximately five years in order to reflect technological advances, changes in learner demographics and the greater acceptance of online learning in the educational environment.

\section{IMPLICATIONS}

This study has several implications for the existing body of knowledge in the IS field as well as for the practice of IS, most especially in the online learning environment with a cross-cultural context. The first implication concerns increasing globalization and the growing body of Webbased technologies, which together have blurred cultural and national boundaries. In other words, national culture and national borders no longer pose a barrier to the collaboration of learners across cultures. Yet at the same time, economically and technologically dominant cultures have largely developed the tools that dictate the nature of online education. It is hoped that this study will contribute to the further study of OLS in the cross-cultural context and help in the improvement or development of OLS better attuned to the cultural needs of non-western societies.

A second implication of this study is its finding that American learners demonstrate a slightly higher perceived OLS effectiveness in term of the course pillar compared to Malaysian learners. This may indicate that American OLS have course materials better suited to the cultural attitudes of its learner base compared to Malaysian OLS. Learning materials and objectives presented in online courses must be developed in a quality way and maintain that quality over time. According to Galusha [25], course content is important because the quality of the course content affects learners' perception of the online course. Poorly designed course material can be a key contributor to learner attrition rates [25]. Simply having course content in an OLS without applying any pedagogical principles to their development is an ineffective way to developing an effective online course [25]. Therefore, having quality online course content better suited to the cultural needs of learners will increase the perceived OLS effectiveness in terms of the course 
pillar.

A third implication of this study is its finding that learners from a low PDD society, such as the United States, demonstrated a slightly higher perceived OLS effectiveness in terms of the course and professor pillars than those learners from a high PDD, such as Malaysia. Based on these findings, a preliminary suggestion might be that OLS course developers or professors create instructional methods more suitable to a high PDD society such as Malaysia. For instance, online learning instructors could encourage high PDD learners to be more active in seeking solutions with minimal guidance. Further, in the context of a high PDD society, such features as interactive videoconferencing might be an effective and valuable addition to an OLS, serving to enhance communications between the professor and learners. In addition, videoconferencing might also be used to validate understanding and provide feedback. This interactivity could provide high PDD learners with a more positive and effective online learning experience than they currently experience. Most importantly, OLS developers and professor could shift their instructional strategies from professor-centered instruction towards learner-centered instruction [27]. According to Wilson [62], this would accommodate the diversity of learner needs.

A fourth implication of this study is its finding that those from a high ICD society such as the United States demonstrated a slightly higher perceived OLS effectiveness in terms of the course and professor pillars than learners from a low ICD society such as Malaysia. Based on these findings, in the context of a low ICD society, OLS course developers or professors should create or design courses that include more activities that are in general more collaborative and less individual-centered in nature. Low ICD society learners often prefer to work in groups, take collective responsibility, and are more likely to speak up within the context of their group than directly to the professor. Therefore, an OLS that included more collaborative activities and socialization might serve to increase perceived OLS effectiveness in the course and professor pillars among low ICD learners.

A fifth implication of this study is its finding that those from a strong UAD society such as Malaysia demonstrated a slightly lower perceived OLS effectiveness in terms of the course and professor pillars than American learners. Based on this finding, in the context of a strong UAD society, Malaysian OLS course developers and instructors should endeavor to create or design courses better structured for learners from a strong UAD society. Such a structured online learning environment is more suitable for strong UAD learners because it better accords with their cultural characteristics. More structured online course content will be better suited to the cultural needs of learners from a strong UAD society and thereby increase the perceived OLS effectiveness in terms of the course pillar.

\section{ACKNOWLEDGEMENTS}

The authors would like to thank all the learners who participated in this study. Further, the authors would like to thank the editor-in-chief and the anonymous reviewers for their careful review and valuable suggestions.

\section{REFERENCES}

[1] Amant, K. (2004). Distance education in a global age: A perspective for internationalizing online learning communities. SIGGROUP Bulletin, 25(1), 13-19.

[2] Anakwe, U. P., Kessler, E. H., \& Christensen, E. W. (1999). Distance learning and cultural diversity: Potential users' perspective. The International Journal of Organizational Analysis, 7(3), 224-243. 
International Journal of Computer Science \& Information Technology (IJCSIT) Vol 10, No 1, February 2018

[3] Au, N., Ngai, E. W. T., \& Cheng, T. C. E. (2002). A critical review of end-user information system satisfaction research and a new research framework. The International Journal of Management Science, 30(6), 451-478.

[4] Bailey, J. E., \& Pearson, S. W. (1983). Development of a tool for measuring and analyzing computer user satisfaction. Management Science, 29(5), 530-546.

[5] Baroudi, J. J., \& Orlikowski, W. J. (1988). A short-form measure of user information satisfaction: A psychometric evaluation and notes on use. Journal of Management Information Systems, 4(4), 44-59.

[6] Bauer, C., Chin, K. L., \& Chang, V. (2000). Web-based learning: Aspects of cultural differences. Proceedings of the Eighth European Conference on Information Systems, Vienna, 1396-1402.

[7] Bray, E., Aoki, K., \& Dlugosh, L. (2008). Predictors of learning satisfaction in Japanese online distance learners. International Review of Research in Open and Distance Learning, 9(3), 1-24.

[8] Bowers, C. A. (1988). The cultural dimensions of educational computing: Understanding the nonneutrality of technology. New York: Teachers College Press.

[9] Cai, S., Jun, M., \& Pham, L. (2007). End user computing satisfaction and its key dimensions: An exploratory study. Proceedings of the Southwest Decision Science Institute Annual conference (SWDSI-35), 725-734.

[10] Chen, S. J., Hsu, C. L., \& Caropreso, E. J. (2006). Cross-cultural collaborative online learning: When the west meets the east. International Journal of Technology in Teaching and Learning, 2(1), 17-35.

[11] Choe, J. (2004). The consideration of cultural differences in the design of information systems. Information \& Management, 41(5), 669-684.

[12] Cushner, K. (2008). Convergence of cross-cultural and intercultural research. International Journal of Intercultural Relation, 32(2), 91-92.

[13] Deng, X., Doll, W. J., Al-Gahtani, S. S., Larsen, T. J., Pearson, J. M., \& Raghunathan, T. S. (2008). A cross-cultural analysis of the end-user computing satisfaction instrument: A multi-group invariance analysis. Information \& Management, 45(4), 211-220.

[14] Doll, W. J., \& Torkzadeh, G. (1988). The measurement of end-user computing satisfaction. MIS Quarterly, 12(2), 259-274.

[15] Doll, W. J., \& Torkzadeh, G. (1991). The measurement of end-user computing satisfaction: Theoretical and methodological issues. MIS Quarterly, 15(1), 5-9.

[16] Durgee, J. F., O'connor, G. C., \& Veryzer, R. W. (1996). Observations: Translating values into product wants. Journal of Advertising Research, 36(6), 90-100.

[17] Edmundson, A. L. (2005). The cross-cultural dimensions of globalization e-learning. International Journal of Information and Communication Technology Education, 1(2), 47-61, April-June.

[18] Ein-Dor, P., \& Segev, S. (1992). End user computing: A cross-cultural study. International Information Systems, 1(1), 124-137.

[19] Ein-Dor, P., Segev, S., \& Orgad, M. (1993). The effect of national culture on IS implications for international information systems. Journal of Global Information Management, 1(1), 33-44.

[20] Etezadi-Amoli, J., \& Farhoomand, A. F. (1991). On end-user computing satisfaction. MIS Quarterly, 15(1), 1-5.

[21] Feather, N. T. (1975). Values in education and society. New York, NY: The Free Press. 
International Journal of Computer Science \& Information Technology (IJCSIT) Vol 10, No 1, February 2018

[22] Feather, N., \& O'Brien, G. E. (1987). Looking for employment: An expectancy-valence analysis of job-seeking behavior among young people. British Journal of Psychology, 78, 251-272.

[23] Gallivan, M., \& Srite, M. (2005). Information technology and culture: Identifying fragmentary and holistic perspectives of culture. Information and Organization, 15(4), 295-338.

[24] Grover, V., Jeong, S. R., Segars, A. H. (1996). Information systems effectiveness: The construct space and pattern of application. Information \& Management, 31(4), 177-191.

[25] Galusha, J.M. (1997). Barriers to Learning in Distance Education. Interpersonal Computing and Technology: An Electronic Journal for the 21st Century, 5(3/4), 6-14.

[26] Heilman, G. E., \& Brusa, J. (2005). An investigation of computer satisfaction in Mexico. Journal of Global Information Technology Management, 8(1), 48-63.

[27] Hammoud, L., Love, S., Baldwin, L., \& Chen, S. Y. (2008). Evaluating WebCT use in relation to students' attitude and performance. International Journal of Information and Communication Technology Education, 4(2), 26-43.

[28] Henry, W. (1976). Cultural values do correlate with consumer behavior. Journal of Marketing Research, 13, 121-127.

[29] Hofstede, G. H. (1980). Culture's consequences: International differences in work-related values. Beverly Hills, CA: Sage.

[30] Hofstede, G. H. (1986). Cultural differences in teaching and learning. International Journal of Intercultural Relation, 10(3), 301-320.

[31] Hofstede, G. H. (1991). Cultures and organizations: Software of the mind. New York, NY: McGrawHill.

[32] Hofstede, G. H. (1993). Cultural constraints in management theories. Academy of Management Executive, 7(1), 81-94.

[33] Hofstede, G. H. (2003). Culture's consequences: Comparing values, behaviors, institutions and organization across nations (2nd ed.). Beverly Hills, CA: Sage.

[34] Hofstede, G. H., \& Bond, M. H. (1998). The Confucius connection: From cultural roots to economic growth. Organizational Dynamic, 4(16), 4-21.

[35] Ilias, A., Yasoa, M. R., Razak, M. Z. A., \& Rahman, R. A. (2007). The study of end-user computing satisfaction (EUCS) on computerized accounting system (CAS) among Labuan F.T government sectors: A case study in the responsibility centres. Labuan e-Journal of Muamalat and Society, 1, 114.

[36] Ives, B., Olson, M. H., \& Baroudi, J. J. (1983). The measurement of user information satisfaction. Communications of the ACM, 26(10), 785-793.

[37] Jones, K. C. (2007). Worldwide E-learning to draw nearly $\$ 53$ billion by 2010. InformationWeek, Retrieved May, 20, 2009, from http://www.informatioweek.co- m/news/intenet/showArticle.jhtml?articleI-D=201311139

[38] Kahle, L. R., \& Kennedy, P. (1988). Using the list of values (LOV) to understand consumers. Journal of Services Marketing, 2(4), 49-56.

[39] Kettinger, W. J., \& Lee, C. C. (1994). Perceived service quality and user satisfaction with the information service function. Decision Sciences, 25(5-6), 737-767. 
International Journal of Computer Science \& Information Technology (IJCSIT) Vol 10, No 1, February 2018

[40] Koc, M. (2005). Individual learner differences in web-based learning environments: For cognitive, affective and social-cultural perspectives. Turkish Online Journal of Distance Education, 6(4), 12-22.

[41] Lee, J. J., \& Lee, K. P. (2007). Cultural differences and design methods for user experience research: Dutch and Korean participants compared. Communications of the ACM, 21-34.

[42] Levy, Y., \& Murphy, K. E. (2002). Toward a value framework for online learning system. Proceedings of the 35th Hawaii International conference on system Sciences (HICSS-35'02), 40-48.

[43] Levy, Y. (2003). A study of learners' perceived value and satisfaction for implied effectiveness of online learning systems. Dissertation Abstracts International, 65(03), 1014A. (UMI No. AAT 3126765)

[44] Levy, Y. (2006). Assessing the value of e-learning systems. Hershey, PA: Idea Group Publishing, Inc.

[45] Malik, N. A., Belawati, T., \& Baggaley, J. (2005). Framework of collaborative research and development on distance learning technology for Asia. The 19th Annual Conference, Association of Asian Open Universities, Jakarta, Indonesia, 1-11.

[46] Munson, J. M., \& Posner, B. Z. (1980). The values of engineers and managing engineers. IEEE Transactions on Engineering Management, 26(2), 55-60.

[47] Oshlyansky, L., Cairns, P., \& Thimbleby, H. (2006). A cautionary tale: Hofstede's VSM revisited. Proceeding of British Human Computer Interaction Conference, 2, 128-132.

[48] Robinson, B. (1999). Asian learner, western models: Some discontinuities and issues for distance educators. In R. Carr, O. J. Jegede, T. M. Wong, \& K. S. Yuen (Eds.), The Asian Distance Learner (pp. 33-48). Hong Kong: The Open University of Hong Kong Press.

[49] Rokeach, M. (1969). Beliefs, attitudes, and values. San Francisco, CA: Jossey-Bass.

[50] Rokeach, M. (1973). The nature of human values. New York, NY: The Free Press.

[51] Rubio-Sanchez, A. (2007). Cultural dimensions and their influence on shopping value. Retrieved from Dissertations and Theses database. (AAT 3296109).

[52] Sánchez-Franco, M. J., Martínez-López, F. J., \& Martín-Vekicia, F. A. (2009). Exploring the impact of individualism and uncertainty avoidance in web-based electronic learning: An empirical analysis in European higher education. Computer \& Education, 52(3), 588-598.

[53] Seddon, P. B., \& Yip, S. K. (1992). An empirical evaluation of user information satisfaction (UIS) measure for use with general ledger accounting software. Journal of Information Systems, 6(1), 7593.

[54] Seddon, P. B., Graeser, V., \& Willcocks, L. P. (2003). Measuring organization IS effectiveness: An overview and update of senior management perspectives. The DATABASE for Advances in Information Systems, 33(2), 11-29.

[55] Shachaf, P. (2008). Cultural diversity and information and communication technology impacts on global virtual teams: An exploratory study. Information \& Management, 45(2), 131-142.

[56] Straub, D. W., Loch, K., Evaristo, R., Karahanna, E., \& Strite, M. (2002). Toward a theory-based measurement of culture. Journal of Global Information Management, 10(1), 13-23.

[57] Sun, P. C., Tsai, R. J., Finger, G., Chen, Y. Y., \& Yeh, D. (2008). What drives a successful elearning? An empirical investigation of the critical factors influencing learner satisfaction. Computer \& Education, 50(4), 1183-1202. 
International Journal of Computer Science \& Information Technology (IJCSIT) Vol 10, No 1, February 2018

[58] Wang, Y. S. (2003). Assessment of learner satisfaction with asynchronous electronic learning systems. Information \& Management, 41(1), 75-86.

[59] Wangpipatwong, T., \& Papasratorn, B. (2007). The influence of constructivist e-learning system on student learning outcomes. International Journal of Information and Communication Technology Education, 3(4), 21-33.

[60] Watson, R., Ho, T., \& Raman, K. (1994). Culture: A fourth dimension of group support systems. Communications of the ACM, 37(10), 45-55.

[61] Whitten, D. (2004). User information satisfaction scale reduction: Application in an IT outsourcing environment. Journal of Computer Information Systems, 45(2), 17-26.

[62] Wilson, B.G. (2004). Designing e-learning environment for flexible activity and instruction. Educational Technology Research \& Development, 52(4), 77-84.

[63] Xiao, L., \& Dsgupta, S. (2002). Measurement of user satisfaction with web-based information systems: An empirical study. Proceedings of the 8th Americas Conference on Information Systems, Dallas, Texas, 1149-1155.

[64] Zhang, D., \& Lowry, P. B. (2008). Issues, limitations, and opportunities in cross-cultural research on collaborative software in information systems. Journal of Global Information Management, 16(1), 6191.

[65] Zhang, D. S., Lowry, P. B., Zhou, L., \& Fu, X. L. (2007). The impact of individualism-collectivism social presence, and group diversity on group decision making under majority influence. Journal of Management Information Systems, 23(4), 53-80.

\section{AUTHOR}

Seng C. Keng received PhD Degree in Information System from Nova Southeastern University. Florida USA. He has more than 15 years of experience in education and more than 10 years of experience in Software industry. His main research interests include e-learning systems, information systems, cultural studies, and early childhood education 